$\begin{array}{cl}\text { Türkiye Tarımsal Araştırmalar Dergisi } & \text { Turk J Agric Res } \\ \text { dergipark.gov.tr/tutad } & \text { 2017, 4(2): 103-108 } \\ \text { O TÜTAD } & \text { ISSN: 2148-2306 } \\ \text { e-ISSN: 2528-858X } & \text { doi: 10.19159/tutad.310565 }\end{array}$

\title{
Soğukta Muhafaza Edilen Brokoli Çeşitlerinin (Brassica oleracea L., var. italica cvs. Belstar ve Beaumont) Depolama Süresi ve Kalite Özellikleri Üzerine Modifiye Atmosfer Paketlemenin Etkisi
}

\author{
Serdar POLAT, Erdinç BAL* \\ Namık Kemal Üniversitesi, Ziraat Fakültesi, Bahçe Bitkileri Bölümü, Tekirdağ, TÜRKIYYE
}

\begin{abstract}
Geliş Tarihi/Received: 01.11 .2016
Kabul Tarihi/Accepted: 04.05.2017

*Sorumlu Yazar/Corresponding Author: ebal@nku.edu.tr

Özet: Bu çalışmada, Tekirdağ ekolojisinde yetiştirilen Belstar ve Beaumont brokoli çeşitlerinin soğukta muhafaza süresi ve kalite özellikleri üzerine modifiye atmosfer paketlemenin (MAP) etkileri araştırılmış̧ır. Ambalajlanan ve kontrol grubu olușturulan brokoli taçları $2 \pm 1^{\circ} \mathrm{C}$ sıcaklık ve $\% 90-95$ oransal nemde 4 hafta süre ile muhafaza edilmiștir. So ğukta muhafaza süresince birer haftalık aralıklar ile ağılık kaybı, toplam fenolik bileşik miktarı, antioksidan kapasitesi, toplam klorofil miktarı ve dış görünüş değerlerindeki değiş̧imler belirlenmiştir. Araştırma sonucunda, kontrol grubu taçlarında modifiye atmosfer paketler de muhafaza edilen taçlara göre daha yüksek ağırlı kaybı meydana gelmiş̧ir. İncelenen her iki çeşitte, depolama süresince toplam fenolik bileşik, antioksidan kapasitesi ve toplam klorofil miktarı bakımından değişkenlikler gözlemlenmekle birlikte, muhafaza süresi sonun da her iki çeşitte MAP uygulanmış taçların daha yüksek içeriğe sahip olduğu tespit edilmiştir. Soğukta muhafaza süresince hem açıkta hem de MAP'da muhafaza edilen brokoli taçlarının dış görünüşün de kayıplar belirlenmiştir. Fakat MAP uygulaması ile dış görün üşte meydana gelen kayıp sınırlandırılmıştır. Sonuç olarak MAP, soğukta muhafaza edilen brokoli taçlarının kalitesini korumak için bir araç olarak kullanılabilece ği önerilebilir.
\end{abstract}

An ahtar Kelimeler: Brokoli, modifiye atmosfer paketleme, antioksidan, ağıllık kaybı, klorofil miktarı

\section{Effect of Modified Atmosphere Packaging on Storage Duration and Quality Characteristics of Broccoli Cultivars (Brassica oleracea L., var. italica cvs. Belstar ve Beaumont)}

\begin{abstract}
In this study, the effects of modified atmosphere packaging (MAP) on the shelf-life and quality characteristics of Belstar and Beaumont broccoli cvs. grown in Tekirdağ ecology were evaluated. Packaged broccoli crowns and control groups were stored at $2 \pm 1{ }^{\circ} \mathrm{C}$ and $90-95 \%$ relative humidity for 4 weeks. Variations in weight loss, total phenolic compound content, antioxidant content, total chlorophyll content and external appearance were determined during cold storage period at weekly intervals. As a result of the research, the weight loss of the control group crowns was higher than that of the crowns which was kept in the modified atmosphere packs.. In both cultivars examined, although variations were observed in terms of total phenolic compound, antioxidant capacity and total chlorophyll content during storage; it was found that the MAP applied heads of both cultivars had higher contents at the end of storage period. During cold storage, significant losses in appearance in both control group and MAP treated heads were observed. But with the MAP application, the loss from external appearance is limited. Thus, it can be suggested that the MAP can be used as a tool to maintain the quality of broccoli crowns stored in the cold.
\end{abstract}




\section{Giriş}

Kıșlık sebzeler arasında yer alan brokoli (Brassica oleracea var. italica), son y1llarda üretimi ve tüketimi hızla artan bir lahanagil sebzesidir. Türkiye İstatistik Kurumu (TÜİK) 2015 y 11 verilerine göre ülkemizde 46.353 ton brokoli üretimi yapılmıştır (Anonim, 2016).

Brokoli, taze bir sebze olarak gittikçe popüler olmaktadır ve hem flavanol glikozidler gibi biyolojik olarak aktif diyet bileşenlerin in, hem de hidroks is inamik asitler, gluko zinolatlar gibi sülfür içeren bileşiklerin, vita minler ve karotenoidler gibi besinsel antioksidanların önemli bir kaynağıdır (Zhang ve Hamauzu, 2004; Singh ve ark., 2007; Lima ve ark., 2014).

Brokolide derim, taçlar üzerindeki çiçek tomurcukları açılmadan önce yapılmaktadır. Çiçek sürgünlerinin iyi geliştiği dönem derim için en uygun dönemdir. Eğer derimde gecikme olursa; çiçek taslakları açılır, çiçeklenme başlar ve sebze olarak değerlendirilen kısımlar sertleşir, odunlaşır ve lezzeti azalır (Anonim, 2011).

Olgunlaş mamış brokoli çiçekleri, derim sonrası yaşamları sırasında hızlı bir yaşlanma ile kolay bozulabilen sebzelerden biridir. Brokolide yaşlanma hızı; genetik mekanizmaların etkiled iği fizyolojik faktörlere de bağlı olarak derim sırasında çiçek tomurcuklarının olgunluğuna, depolama sicaklığına, atmosfer bileşimine ve depolama süresine bağlıdır (Lipton ve Haris, 1974). Yapılan çalış malarda brokoli taç larının 0-4 ${ }^{\circ} \mathrm{C}$ sicaklik ve \% 90-95 oransal nemli depolarda birkaç hafta muhafaza edilebildiği belirtilmiştir (Shewfelt ve ark., 1983; Kader, 2002).

Brokoli yaşlanmasının en çok görülen belirtileri; taçlarda solma, klorofil yıkımına bağlı olarak çanak yaprakların sararması ve çiçeklerin açmasıdır. Başlar üzerindeki olgunlaşmamış çiçek taslakları derimden sonra da gelişmeye devam eder. $\mathrm{Bu}$ nedenle derim edilen brokoliler oda sıcaklığında yaklaşık üç gün içinde sararır, pazar değerini ve yeme kalitesini kaybeder. Soğutma, modifiye atmosfer ve ambalajlamanın farklı tiplerini içeren pek çok teknik, brokolinin derim sonras1 ömrünü uzatmak için kullanılmaktadır (Costa ve ark., 2005). Brokolide modifiye atmosferli paketleme (MAP) karbondioksit $\left(\mathrm{CO}_{2}\right)$ girişine izin verip, oksijen $\left(\mathrm{O}_{2}\right)$ seviyesini a zaltarak taçlarda sararma ve yumuşamayı önleyerek depolama süresince kalitenin korunmasin1 sağlayabilmektedir (Serrano ve ark., 2006; Fernandez-Leon ve ark., 2013).

Brokoli için düşük sıcaklık ve yüksek bağıl nem raf ömrünü uzatmak için en önemli koşullardır. Soğutma, yaşlanma etkilerini azaltma ve kalitesini sürdürmede en yaygın yol olarak kullanılmaktadır. Düşük sıcaklık ve yüksek bağıl nem ile klorofil yıkım hızı yavaşlamakta, solunum oranı ve etilen üretimi düşmekte, buna ilave olarak etilen hassasiyeti azalmaktadır (Makhlouf ve ark., 1989; Gnanasekharan ve ark., 1992).

Bu çalışmada; soğukta muhafaza edilen Belstar ve Beaumont brokoli çeşidinin ağırlık kaybı, bazı biyoaktif bileşikleri ve $\mathrm{d}$ 1ş görünüşü üzerine MAP uygulamasinın etkin liğini belirlemek amaçlanmıştır.

\section{Materyal ve Yöntem}

Araştırmada, Tekirdağ ili Namık Kemal Üniversitesi Ziraat Fakültesi Araştırma ve Uygulama Bahçesi'nde yetiştirilmiş olan F1 brokoli çeşitlerinden Belstar ve Beaumont çeşidine ait taçlar kullanılmıştır. Brokoli taçlarının derimi tomurcukların kapalı olduğu dönemde yapılmış, yapraklar temizlendikten sonra 200-300 g ağırlı̆ ındaki taçlar deneme materyali olarak kullanılmıştır.

Araştırmada her iki çeşitte de kontrol grubu taçlar açıkta tabaklara konulmuştur. MAP uygulamasında ise, taçlar tabaklara konularak polietilen bazlı poşetler ile paketlen miştir. Brokoli taçlarında muhafaza öncesinde başlangıç analizleri yapılmıştır. Ambalajlanan ve kontrol grubu oluşturulan brokoli taçları $2 \pm 1{ }^{\circ} \mathrm{C}$ sıcaklık ve $\%$ 90-95 oransal nemde 4 hafta süre ile muhafaza edilmiştir. Taçlardan her hafta örnekler alınarak, muhafaza süresince bunlarda meydana gelen ağırlık kaybı (\%), toplam fenol miktarı (mg GAE $\left.100 \mathrm{~g}^{-1}\right)$, antioksidan kapasitesi (mg Asc $100 \mathrm{~g}^{-1}$ ), toplam klorofil miktarı ( $\mu \mathrm{g} \mathrm{g}^{-1}$ ) (A ğar ve ark., 1997) ve diş görünüş (1-9 skalası; 1-3= pazarlanamaz, 5= pazarlanabilir, $7=$ iyi, $9=$ çok iyi) değerlerindeki değişimler belirlenmiştir. Örneklerin toplam fenolik madde tayini FolinCiocalteu yöntemi ile (Slinkard ve Singleton, 1977), antioksidan kapasiteleri ise DPPH (2,2diphenyl-1-picrylhydrazyl) yöntemi ile (BrandWilliams ve ark., 1995) spektrofotometrik olarak belirlenmiştir.

Deneme, tesadüf parselleri deneme desenine göre 3 tekerrürlü olarak planlanmış ve her tekerrürde 3 adet paket (ortalama $500 \mathrm{~g}$ ) olacak şekilde kurulmuştur. Denemeden elde edilen veriler SPSS istatistik paket programı kullanılarak analize tabi tutulmuşlardır $(\mathrm{P} \leq 0.05)$. Sonuçlar ortalama \pm standart hata olarak belirtilmiştir.

\section{Bulgular ve Tartış ma}

Bro kolide derim sonrası taçlarda meydana gelen en önemli değişimlerden birisi taçların bünyesindeki 
suyun azalması olup, taçların ağ ırlıklarında değişimlere neden olmaktadır (Eşiyok ve ark., 2010). Taçlarda meydana gelen ağırlık kayıplarına ilişkin değerler Şekil 1'de verilmiştir. Araştırmada MAP uygulaması brokoli taçlarında su kaybını önemli derecede $(\mathrm{P} \leq 0.05)$ sinırlandırmıștır. Benzer sonuçlar; Jia ve ark. (2009), Sabır (2012) ve Fernandez-Leon ve ark. (2013)'nın yaptıkları çalış malarda da tespit edilmiştir. Çeşitler arasında Beau mont çeşidinin ortalama ağırlık kayıpları daha düşük seviyede bulunmuştur. Birinci haftada Belstar çeşidinde kontrol grubunda \% 5.2, MAP uygulamasında \% 1.5' lik bir kay ıp gerçekleşirken; 4. haftada kontrol grubunda \% 19.3 ve MAP uygulamasında \% 6.6'lik bir ağırlık kaybı tespit edilmiştir. Beaumont çeşidinde ise 1. haftada kontrol grubunda \% 4.9, MAP uygulamasinda $\%$ 1.6'lık bir kayıp gerçekleşirken; 4. haftada kontrol grubunda \% 18.6 ve MAP uygulamasinda \% 5.4'lük bir ağırlık kaybı belirlenmiştir. Eşiyok ve ark. (2010) da 24 gün süresince buzdolab1 koşullarında muhafaza ettikleri brokoli taçlarında \% 27'lere varan ağırlık kayıplarının olduğunu bildirmiştir.
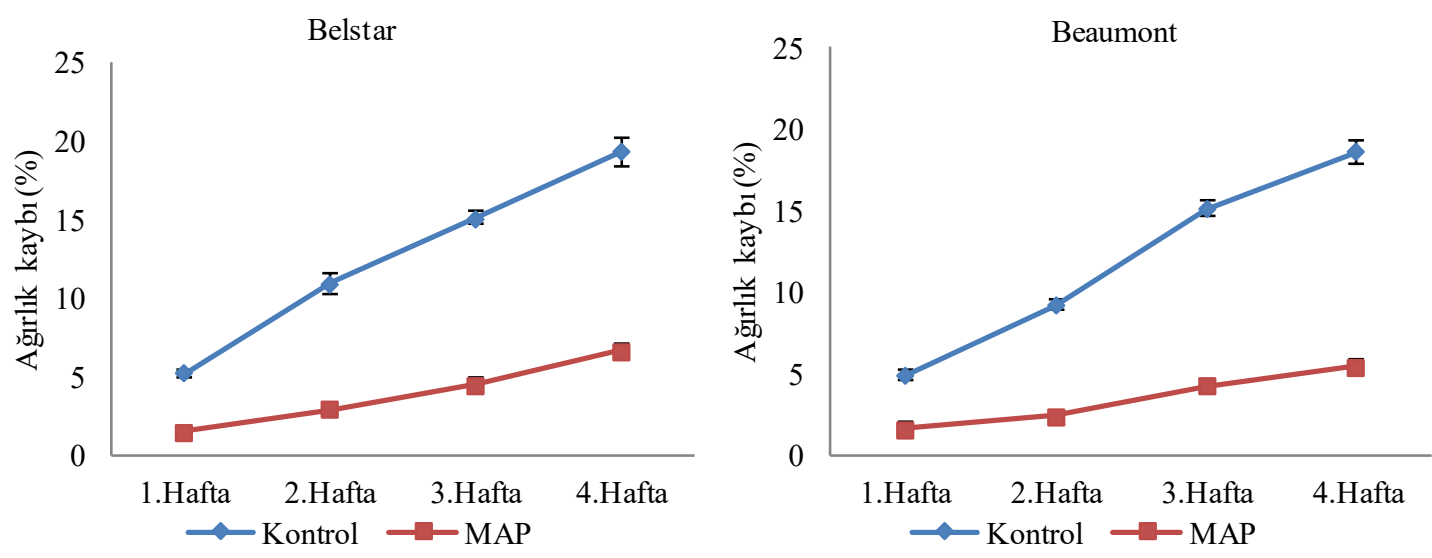

Şekil 1. Depolama periyodu boyunca brokolilerde meydana gelen ağırlık kayıpları

Fenolik bileşikler, meyve ve sebzelerde tat ve renk üzerine etkilidirler (Karaçalı, 2002). Brokoli, yapısında önemli oranda fenolik bileşik bulunduran bir sebzedir. Ancak miktarı; çeşide, yetiştirme koşullarına, olgunluk seviyesine ve depo koşullarına göre farklılıklar göstermektedir (Bahorun ve ark., 2004). Yapılan çalış mada her iki çeşitte de uygulamaların ve muhafaza süresinin etkisi istatistiki açıdan önemli bulunmuştur $(\mathrm{P} \leq 0.05)$. Derim döneminde toplam fenol miktarı Belstar çeşidinde $133.1 \mathrm{mg}$ GAE $100 \mathrm{~g}^{-1}$, Beaumont çeşidinde ise $171.3 \mathrm{mg}$ GAE $100 \mathrm{~g}^{-1}$ olarak bulunmuştur ve her iki çeşidin kontrol grubunda depolama sonunda, baş langıç değerlerine göre düşüşler tespit edilmiştir (Şekil 2). Depolama periyodu sonunda bu düşüşlerin yüksek oranda
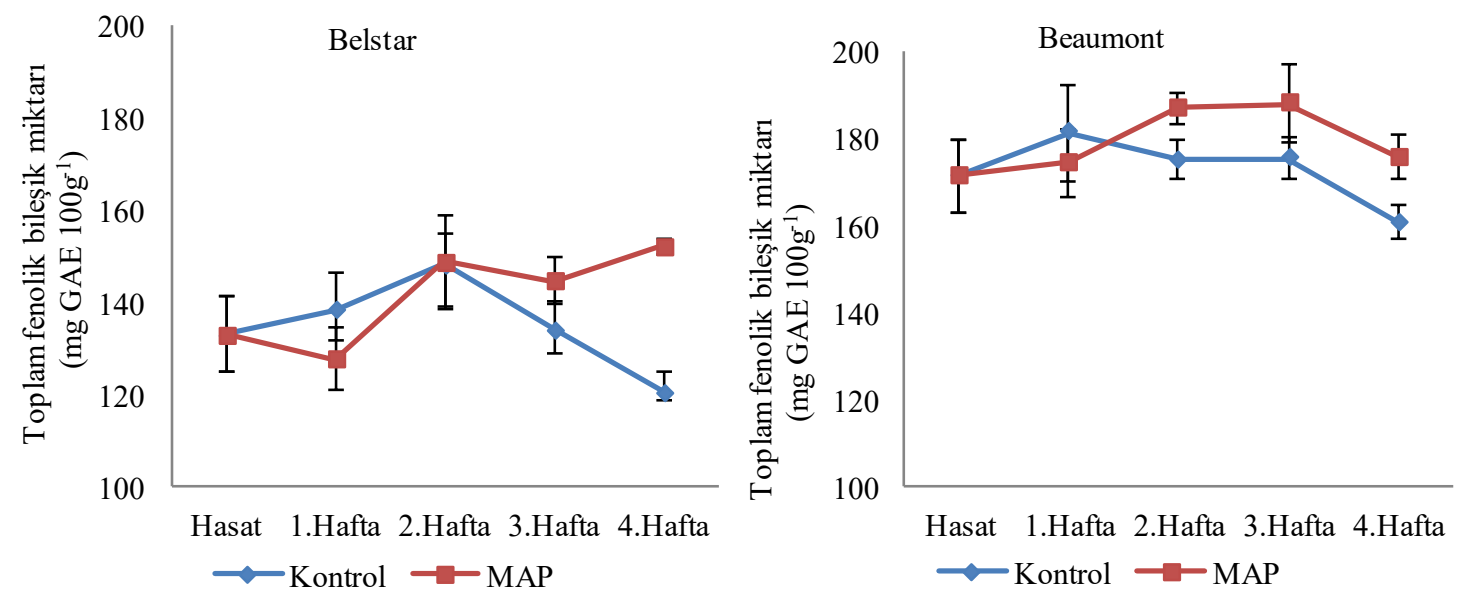

Şekil 2. Depolama periyodu boyunca brokolilerde toplam fenolik bileşik miktarında meydana gelen değişimler 
ağırlık kaybı ve yaşlanmaya bağlı olarak pazarlanabilir değerini yitirmiş olmalarından kaynaklanabileceği düşünülmektedir. MAP uygulamalarında ise Belstar çeşidi (152.1 mg GAE $100 \mathrm{~g}^{-1}$ ) ve Beaumont çeşidinin (175.5 mg GAE $100 \mathrm{~g}^{-1}$ ) başlangıca göre toplam fenol miktarlarını önemli oranda koruduğu belirlen miştir. Serrano ve ark. (2006) ise $5{ }^{\circ} C^{\prime}$ de 12 gün süreyle hem ambalajsiz, hem de MAP yapılarak depoladikları brokoli taçlarında, toplam fenol miktarında önce artış, depolama sonuna doğru ise azalış tespit etmiştir. Ancak bu azalış, çalışma sonuçlarına benzer şekilde MAP uygulananlarda daha sinırlı kalmıştır.

Brokoli antioksidan aktivitesi içeriği bakımından zengin sebzeler arasında yer almakta ve çeşitlere göre miktarı farklılık göstermektedir (Singh ve ark., 2007). Araştırmada; Belstar çeşidinde MAP uygulamasının ve muhafaza süresinin antioksidan kapasitesine etkisi istatistiki açıdan önemli $(\mathrm{P} \leq 0.05)$ bulunurken, Beaumont çeşidinde ise sadece muhafaza süresinin etkisi önemli bulunmuştur. Elde edilen bulgulara göre, antioksidan içeriği depolama süresine bağlı olarak artış ve azalış ş eklinde değişim gösterirken, her iki çeşitte de MAP uygulamalarında bu değişimler daha sınırlı gerçekleşmiştir (Şekil 3). Yapılan farklı çalışmalarda da MAP uygulamalarının antioksidan aktivitesini korumada etkili olduğu bildirilmiştir (Nath ve ark., 2011; Fernandez-Leon ve ark., 2013). Belstar çeşidinde en düşük antioksidan içeriği 4. haftada kontrol uygulamasinda (71.4 mg Asc $100 \mathrm{~g}^{-1}$ ), en yüksek antioksidan içeriğ $\mathrm{i}$ ise 1 . haftada MAP uygulamasinda (123.6 mg Asc $100 \mathrm{~g}^{-1}$ ) tespit edilmiştir. Beaumont çeşidinde ise en düşük antioksidan içeriği 4. haftada kontrol uygulamasinda (112.3 mg Asc $100 \mathrm{~g}^{-1}$ ), en yüksek antioksidan içeriğ $\mathrm{i}$ ise 1 . haftada MAP uygulamasinda (123.4 mg Asc $\left.100 \quad \mathrm{~g}^{-1}\right)$ belirlenmiştir. Leja ve ark. (2001) ve Lima ve ark. (2014) da depolama sırasında brokoli çiçeklerinin antioksidan özelliği üzerine yaptıklan bir çalışmada, depolanmış brokolinin çiçek tomurcuklarinda belirlenen toplam antioksidan aktivitesinin belirgin bir artış gösterdiğini tespit etmiştir.
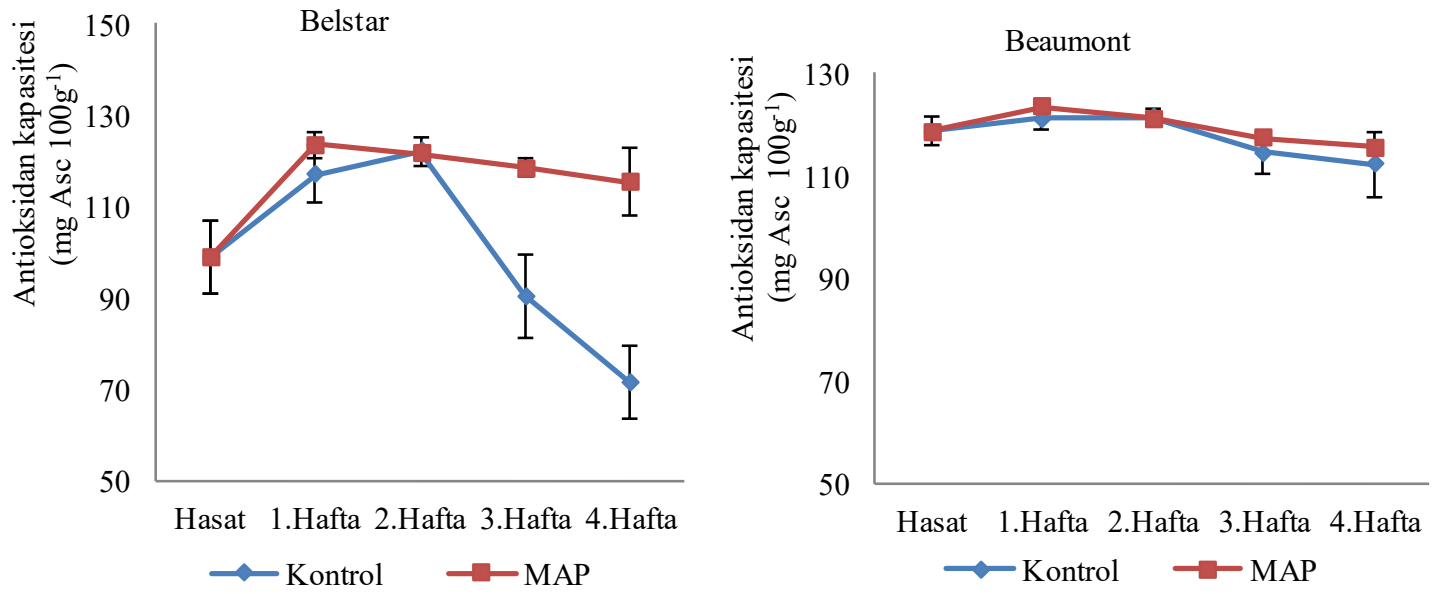

Şekil 3. Depolama periyodu boyunca brokolilerin antioksidan kapasitesindeki değişimler

Meyve ve sebzelerde tüketicin in seçebileceği ilk kalite ö zelliklerinden biri renktir. Tüm bitkisel dokuların yeşil renkleri, klorofil olarak bilinen pigmentten kaynaklanmaktadır. Bir sebzede bulunan toplam klorofil miktarı, sebzenin çeşid ine ve yetişme koşullarına göre önemli düzeyde değişebilmektedir. Depolan ma sıras inda sebzelerin yeşil renginin sarıya dönüşmesi klorofilin parçalan masından kaynaklanmaktadır (Cemeroğlu ve ark., 2001). Araştırmada da muhafaza süresince brokoli taçlarında saptanan klorofil kayıpları önemli $(\mathrm{P} \leq 0.05)$ olmuştur (Şekil 4). Özellikle kontrol grubundaki taçların muhafaza başlangıcındaki parlak yeşil renklerini muhafaza süresince koruyamadikları ve MAP uygulamalarına göre klorofil parçalan masın ın daha hızlı olduğu görülmüştür. Brokoli taçlarındaki toplam klorofil miktarına MAP uygulamasının olumlu etkisi, ambalaj içinde oluşan $\mathrm{CO}_{2}$ ve $\mathrm{O}_{2}$ konsantrasyonunun solunum hızını düşürmesi, etilenin etkisini azaltması ve klorofil parçalanması dâhil parçalanma olaylarını yavaşlatmasından kaynaklandığ 1 düşünülmektedir. Her iki brokoli çeşidinde de en yüksek klorofil miktarı derim döneminde belirlenmiştir. Belstar ve Beaumont brokoli çeșitlerinin her ikisinde de, en düşük toplam klorofil içeriği 4. haftada kontrol gruplarında $\left(121.6 \mu \mathrm{g} \mathrm{g}^{-1}\right.$ ve $\left.124.2 \mu \mathrm{g} \mathrm{g} \mathrm{g}^{-1}\right)$ tespit 
edilmiştir. Yapılan pek çok çalışmada da derim sonrası depo koşullarına ve uygulamalara bağlı olarak brokoli taçlarında klorofil parçalanmasının gerçekleştiği be lirtilmektedir (Costa ve ark., 2005; Sabır, 2012; Lima ve ark., 2014; Topçu ve ark., 2015).
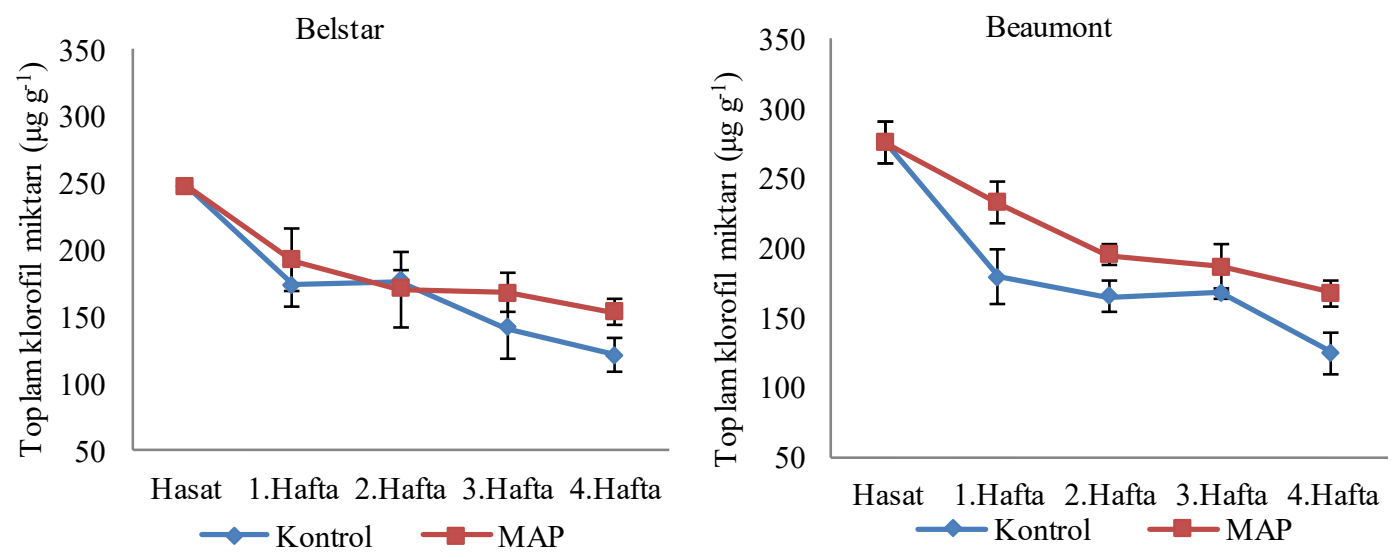

Şekil 4. Depolama periyodu boyunca brokolilerde toplamklorofil miktarında meydana gelen değişimler

Taze brokolinin diş görünüm kalitesinin korunması; ağırlık kayıpların ın azaltılması, taç üzerindeki çiçeklerin açmaması ve olan klorofil kaybına bağlı olarak çiçek to murcuklarının sararmasının engellenmesi ile mümkün olmaktadır.
Yapılan çalışmada brokoli taçlarının dış görünüş değerlendirmesi 1'den 9'a kadar verilen puan skalasına göre belirlenmiş ve elde edilen veriler istatistiki açıdan önemli bulunmuştur (Şekil 5). Muhafaza periyodu boyunca haftalık olarak
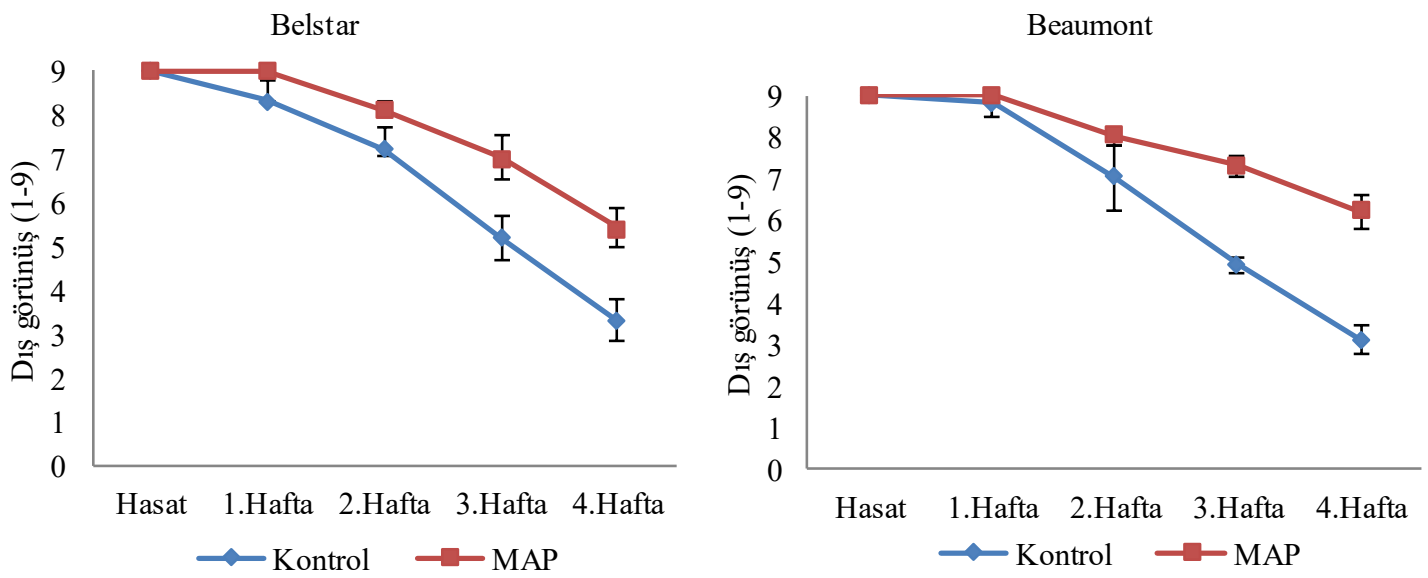

Şekil 5. Depolama periyodu boyunca brokolilerin dış görünüşünde meydana gelen değişimler

yapılan gözlemler sonucunda tüm uygulamalarda brokoli taçlarında herhangi bir patolojik kayıplara rastlanmamıştır. Her iki çeşitte de 3. haftadan itibaren özellikle kontrol uygulamas ındaki taçlarda su kaybı artışına paralel olarak pörsüme ve buruşma şeklinde görünüş bozukluğu ile sararma şeklinde renk kaybı meydana geldiği gözlen miştir. Ancak MAP uygulamasındaki taçlarda rengin depolama süresince korunduğu ve su kaybından ileri gelen pörsümenin de daha düşük düzeyde kaldığ 1 tespit edilmiștir. Muhafaza süresi sonunda Belstar çeşidi taçları ortalama 5.4, Beaumont çeşidi taçları ise ortalama 6.2 puan almıştır. Nitekim modifiye atmosfer ambalajlarının genellikle ürünlerde su kaybı, solma ve buruşmayı azaltt $\breve{g ̆}_{1}$ bildirilmiştir (Karaçal1, 2002). Dördüncü haftada her iki çeşitte de kontrol grubunda bulunan brokolilerin (3.3 ve 3.1) puan skalasına göre pazarlanabilir özelliğini kaybettiği belirlenmiştir. 


\section{Sonuçlar}

Sonuç olarak, brokolinin muhafazasında modifiye atmosfer ambalajının kullanılması ağırlık kayıplarını azaltarak ve biyokimyasal bileşiklerin değişimlerini yavaşlatarak depolanma ömrünü uzatmıştır. Çeşitler arasında ise Beaumont brokoli çeşidinin Belstar çeşidine göre incelenen parametreler bakımından kalitesini daha iyi koruduğu belirlenmiştir. Sonuç olarak açıkta muhafaza edilen brokoli taçlarının 2 hafta, MAP uygulanmış brokolilerin ise 4 haftaya kadar $2{ }^{\circ} \mathrm{C}$ ve \% 90-95 oransal nemli ortamda başarıla depolanabileceği belirlenmiştir.

\section{Kaynaklar}

Ağar, İ.T., Kafkas, S., Kaşka, N., 1997. Variation in kernel chlorophyll content of different pistachio varieties grown in six countries. Acta Horticulturae, 470: 372-377.

Anonim, 2011. Brokoli Yetiştiriciliği. http://megep.meb. gov.tr/ (Erişim tarihi: 20.06.2016).

Anonim, 2016. Bitkisel Üretim İstatistikleri. www.tuik. gov.tr (Erişim tarihi: 01.12.2016).

Bahorun, T., Luximon-Ramma, A., Crozier, A., Aruoma, O.I., 2004. Total phenolic, flavonoid, proanthocyanidin and vitamin $\mathrm{C}$ levels and antioxidant activities of mauritian vegetables. Journal of the Science of Food and Agriculture, 84(12): 1553-1561.

Brand-Williams, W., Cuvelier, M.E., Berset, C., 1995. Use of a free radical method to evaluate antioxidant activity. Food Science and Technology, 28(1): 2530.

Cemeroğlu, B., Yemenicioğlu, A., Özkan, M., 2001. Meyve ve Sebzelerin Bileşimi Soğukta Depolanmaları. Gıda Teknolojisi Derneği Yayınları No: 24, Ankara.

Costa, M.L., Civello, P.M., Chaves, A.R., Martinez, G.A., 2005. Effect of hot air treatments on senescence and quality parameters of harvested broccoli heads. Journal of the Science of Food and Agriculture, 85(7): 1154-1160.

Eşiyok, D., Salman, M.H., Şen, F., Aşçıŏul, T.K., 2010. Bazı brokkoli çeşitlerinde raf ömrü süresince kalite değişimlerinin belirlenmesi. Ege Üniversitesi Ziraat Fakültesi Dergisi, 47(1): 79-86.

Fernandez-Leon, M.F., Fernandez-Leon, A.M., Lozano, M., Ayuso, M.C., Amodio, M.L., Colelli, G., Gonzalez-Gomez, D., 2013. Retention of quality and functional values of broccoli 'Parthenon' stored in modified atmosphere packaging. Food Control, 31(2): 302-313.

Gnanasekharan, V., Shewfelt, R.L., Chinnan, M.S., 1992. Detection of color changes in green vegetables. Journal of Food Science, 57(1): 149154.

Jia, C.G., Xu, C.J., Wei, J., Yuan, J., Yuan, G.F., Wang, B.L., Wang, Q.M., 2009. Effect of modified atmosphere packaging on visual quality and glucosinolates of broccoli florets. Food Chemistry, 114(1): 28-37.

Kader, A.A., 2002. Postharvest technology of horticultural crops. University of California Agriculture and Natural Resources, Nat. Resources, Oakland.

Karaçal1, İ., 2002. Bahçe Ürünleri Muhafazası ve Pazarlanmas1. Ege Üniversitesi Ziraat Fakültesi Yayınları, No: 494, İzmir.

Leja, M., Mareczek, A., Starzynska, A., Rozek, S., 2001. Antioxidant ability of broccoli flower buds during short-term storage. Food Chemistry, 72(2): 219-222.

Lima, G.P., Machado, T.M., Oliveira, L.M., Borges, L.S., Pedrosa, V.A., Vanzani, P., Vian ello, F., 2014. Ozonated water and chlorine effects on the antioxidant properties of organic and conventional broccoli during postharvest. Scientia Agricola, 71(2): 151-156.

Lipton, W.J., Haris, C.M., 1974. Controlled atmosphere effects on the market quality of stored broccoli. Journal of the American Society for Horticultural Science, 99: 200-205.

Makhlouf, J., Castaigne, F., Arul, J., Willemot, C., Gosselin, A., 1989. Long-term storage of broccoli under controlled atmosphere. HortScience, 24: 637639.

Nath, A., Bagchi, B., Misra, L.K., Deka, B.C., 2011. Changes in postharvest phytochemical qualities of broccoli florets during ambient and refrigerated storage. Food Chemistry, 127(4): 1510-1514.

Sabır, F.K., 2012. Postharvest quality response of broccoli florets to combined application of 1methylcyclopropene and modified atmosphere. Agricultural and Food Science, 21(4): 421-429.

Serrano, M., Martinez-Romero, D., Guillen, F., Castillo, S., Valero, D., 2006. Maintenance of broccoli quality and functional properties during cold storage as affected by modified atmosphere packaging. Postharvest Biology and Technology, 39(1): 61-68.

Shewfelt, R.L., Batal, K.M., Heaton, E.K., 1983. Broccoli storage: Effect of N6- benzyladenine, packaging, and icing on color of fresh broccoli. Journal of Food Science, 48(6): 1594-1597.

Singh, J., Upadhy ay, A.K., Prasad, K., Bahadur, A., Rai, M., 2007. Variability of carotenes, vitamin C, E and phenolics in Brassica vegetables. Journal of Food Composition and Analysis, 20: 106-112.

Slinkard, K., Singleton, V.L., 1977. Total phenol analysis: Automation and comparision with manual method. American Journal of Enology and Viticulture, 28(1): 49-55.

Topçu, Y., Doğan, A., Kasımoğlu, Z., Nadeem, N.S., Polat, E., Erkan, M., 2015. The effects of UV radiation during the vegetative period on antioxidant compounds and postharvest quality of broccoli (Brassica oleracea L.). Plant Physiology and Biochemistry, 93: 56-65.

Zhang, D., Hamauzu, Y., 2004. Phenolics, ascorbic acid, carotenoids and antioxidant activity of broccoli and their changes during conventional and microwave cooking. Food Chemistry, 88(4): 503-509. 